\title{
Tradisi Keislaman Masyarakat Sunda pada Abad ke-19
}

\author{
Agung Purnama \\ Prodi Sejarah Peradaban Islam, Fakultas Adab dan Humaniora, \\ UIN Sunan Gunung Djati Bandung \\ Email: agungpurnama@uinsgd.ac.id
}

\begin{abstract}
This paper analyzes the religiosity of the Sundanese people in a historical approach, to be precise around the 19th century. The method used is the Historical Method which consists of heuristics, criticism, interpretation, and historiography stages. The results of the study show that the Sundanese people are known as religious people. Islam as a religion adopted by most of the Sundanese Tatar population has been acculturated with the local culture and with the noble values inherited by the Karuhun. In Sundanese society, Islamic teachings are often expressed with the taste of local traditions. Instead, local traditions are often given the breath of Islam, which further strengthens the religiosity of its adherents. In addition to carrying out the basic religious shari'ah, the religious expression of the Sundanese people is present in the form of religious holidays which are commemorated lively. Likewise, the stages of a person's life, such as birth, childhood, marriage, until death, have religious and cultural instruments attached to them.
\end{abstract}

Keywords: Islamic Tradition, religious culture, religiiousity, Sundanese

\section{Pendahuluan}

Pada dasarnya, Islam itu agama, bukan budaya dan bukan tradisi. Akan tetapi dapat dipahami bahwa Islam tidak anti budaya dan tidak anti tradisi. Dalam menyikapi budaya dan tradisi yang berkembang di luar Islam, Islam akan menyikapinya dengan bijaksana, korektif dan selektif. Ketika sebuah tradisi dan budaya tidak bertentangan dengan agama, maka Islam akan mengakui dan melestarikannya. Namun kemudian, ketika suatu tradisi dan budaya bertentangan dengan nilai-nilai agama, maka Islam akan memberikan beberapa solusi, seperti menghapus budaya tersebut, atau melakukan islamisasi dan atau meminimalisir kadar mafsadah dan madharat budaya tersebut. Namun ketika suatu budaya dan tradisi masyarakat yang telah berjalan tidak dilarang dalam agama, maka dengan sendirinya menjadi bagian yang integral dari syari'ah Islam. 
Paradigma demikian menimbulkan fakta bahwa datangnya Islam bukan untuk memberangus budaya setempat. Meminjam istilah $\mathrm{KH}$. Abdurrahman Wahid, "pribumisasi Islam" merupakan upaya "rekonsiliasi" Islam dengan kekuatan-kekuatan budaya setempat, agar budaya lokal itu tidak hilang. Pribumisasi juga bukan upaya mensubordinasikan Islam dengan budaya lokal, karena Islam harus tetap pada sifat Islamnya ${ }^{1}$. Di Nusantara, tradisi dan budaya setempat kerap menjadi sistem pengimplementasian ajaran agama Islam. Islam yang sejatinya merupakan agama pendatang "diterjemahkan" ke dalam konteks struktur sosial budaya yang telah lebih dahulu ada, sehingga hal itu menjadi ciri khas Islam di Nusantara yang tidak dimililiki oleh negeri lain, termasuk oleh negeri di mana Islam lahir.

Pada masyarakat Jawa Barat (Sunda), “domestikasi” simbol-simbol Islam telah menjadikan sesuatu yang berasal dari luar itu dapat dirasakan sebagai pusaka yang otentik yang seolah dihasilkan kebudayaan setempat. Ungkapan "Sunda Islam" dan "Islam nyunda" dibuktikan oleh sebuah kenyataan bahwa sebagian besar orang Sunda memeluk agama Islam, dan menjadikan Islam sebagai salah satu ciri jati diri. Mudahnya Islam berakulturasi dengan budaya Sunda juga tidak terlepas dari adanya persamaan antara hakikat ajaran Islam dengan keyakinan purbawi Sunda. Misalnya, Sunda pra-Islam yang mempercayai adanya Sanghyang Tunggal, memiliki persamaan dengan konsep Tauhid-nya agama Islam. Juga, Sunda yang begitu apresiatif pada alam, dikuatkan dengan konsep rahmatan lil alamien-nya Islam. Nilai-nilai Sundawi lain, seperti "silih asah silih asuh silih asih", dikuatkan dengan paradigma Islam tentang rohman dan rohim-nya Allah SWT, atau kesadaran diri yang dibahasakan dalam istilah "mulih ka jati mulang ka asal", sangat erat kaitann Inna lillahi wainna ilaihi rodjiun. Ketika fiqih Islam menawarkan konsep "haram" bagi sesuatu yang dilarang atau ditabukan, Sunda memberikan konsep alternatif dengan sebutan "pamali" sebagai sebuah kearifan. Pada akhirnya, ajaran Islam dan nilai luhung kasundaan adalah dua entitas yang selalu seiring seirama, saluyu spihanean.

Berangkat dari kesamaan akar teologis tersebut, hampir keseluruhan ekspresi budaya Sunda banyak mengandung nilai-nilai Islam yang mendalam. Banyak idiom yang menjadi pedoman hidup orang Sunda, baik sebagai individu dan keluarga, maupun sebagai anggota masyarakat, bersumber dari

\footnotetext{
${ }^{1}$ Abdurrahman Wahid, Islamku, Islam Anda, Islam Kita, Agama Masyarakat Negara

Demokrasi (Jakarta: Wahid Institut, 2006), xxx.
} 
Al-Quran dan Sunnah Rasulullah SAW yang diadaptasi dengan selera Sunda. Seperti istilah "pardu kasambut, sunat kalampah"2 sebuah ungkapan tidak asing di lidah dan telinga orang Sunda. ${ }^{3}$ Secara garis besar, tulisan ini mengkaji dan memaparkan tentang tradisi-tradisi keagamaan yang diekspresikan oleh masyarakat Sunda.

\section{Metode Penelitian}

Untuk mengkaji permasalahan ini, metode yang penulis gunakan adalah metode sejarah, dengan tekhnik studi literatur. Richard F Clarke dalam menjelaskan bahwa, secara singkatnya, metode sejarah dapat didefinisikan sebagai sebuah sistem dan prosedur yang benar untuk pencapaian kebenaran sejarah. Metode sejarah ini diartikan juga sebagai seperangkat prinsip dan aturan sistematis yang dimaksudkan untuk membantu dalam pengumpulan sumber atau jejak-jejak sejarah, menilainya secara kritis, dan kemudian menyajikan suatu sintesis (dalam bentuk tertulis) dari hasil yang dicapai ${ }^{4}$. Jadi ringkasnya, metode sejarah itu terdiri dari empat tahapan, yaitu heuristik (mencari dan menemukan sumber), kritik (verifikasi, baik secara ekstrernal maupun internal untuk menguji kredibilitas dan otentisitas sumber), interpretasi (penafsiran), dan historiografi (penulisan sejarah).

\section{Hasil dan Pembahasan}

Pengekspresian ajaran agama yang dibalut budaya pada masyarakat Islam Sunda pertama dapat dilihat dari bentuk bangunan masjid sebagai pusat keagamaan orang Islam. Tiga pokok utama ajaran agama yang mencakup Iman, Islam dan Ihsan secara tersirat dari perwujudan atap masjid. Seperti pada umumnya masjid di pulau Jawa, Masjid-masjid klasik yang terdapat di wilayah Jawa Barat juga memiliki atap tumpang, tiga atau lebih yang semakin ke atas akan semakin lancip ${ }^{5}$. Selain itu, masjid-masjid tersebut keadaannya tidak memiliki menara untuk mengumandangkan adzan. Adzan dikumandangkan cukup di dalam masjid saja. Oleh karena itu, sebelum adanya

\footnotetext{
${ }^{2}$ Maksud dari istilah tersebut adalah praktik keagamaan yang sifatnya wajib (fardu) dapat terlaksana dan amaliah yang sunah pun dapat terpenuhi.

${ }^{3}$ Usep Romli, "Menyambut Muktamar Nu Ke 33," Opini Pikiran Rakyat, July 30, 2015, 5.

${ }^{4}$ Gilbert J.S.J. Garraghan, A Guide To Historical Method (New York: Fordham University Press, 1957), 33.

${ }^{5}$ Nina Herlina Lubis, Sejarah Perkembangan Islam Di Jawa Barat (Bandung: Yayasan Masyarakat Sejarawan Indonesia Jawa Barat, 2011), 242.
} 
teknologi pengeras suara, kentongan dan bedug sangat efektif sebagai alat penanda tiba waktu sholat sekaligus sebagai tanda penggilan sholat berjamaah di masjid.

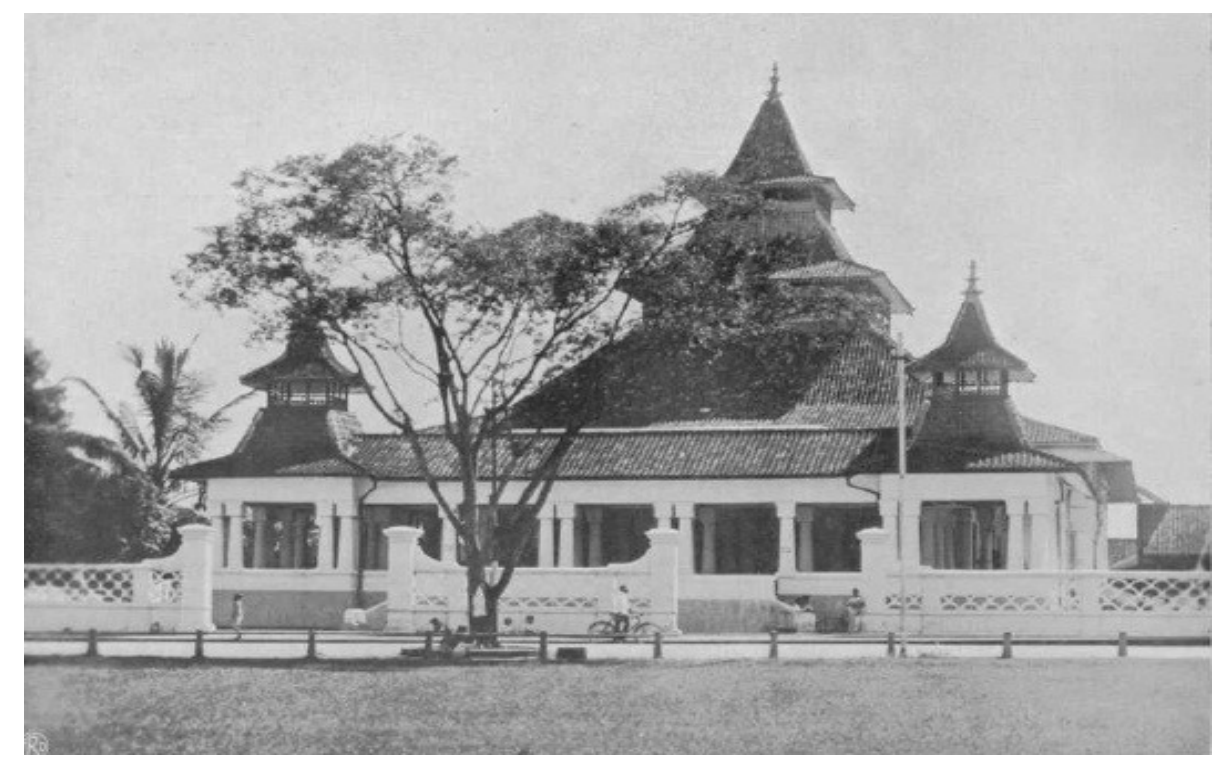

Masjid Agung Bandung sekitar tahun $1931^{6}$

Di Tatar Sunda, juga terdapat masjid-masjid kecil semacam langgar yang disebut "Tajug" yang berfungsi selain untuk tempat shalat berjamaah, juga sering dijadikan sebagai tempat "ngawuruk" (mengajar) ngaji Al-Qur'an, atau hal-hal lain terkait syariat dan peribadatan bagi anak-anak kecil dan remaja oleh tokoh agama setingkat ustadz atau kyai desa.

Op Java is in bijna elk dorp een bedehuisje, langgar of zooals in de Pasoendan tadjoeg geheeten, waar een deel van de jeugd samenkomt gedurende een paar uren van den dag om onderricht te ontvangen. Als onderwijzer treedt veelal de dorpspriester op of iemand anders die er de geschiktheid voor heeft. Het onderwijs omvat in de eerste plaats het werktuigelijk opzeggen van enkele Koeran fragmenten (Di Jawa, hampir di setiap desa terdapat rumah ibadah, langgar, atau di Pasundan biasa disebut tadjoeg, tempat sebagian pemuda berkumpul selama beberapa jam dalam sehari untuk mengaji. Biasanya kyai desa atau siapapun yang memiliki kemampuan untuk bertindak sebagai guru.

\footnotetext{
${ }^{6}$ Masdjid Dan Makam Doenia Islam (Weltervreden: Balai Pustaka, 1926), 32.
} 
Pertama-tama yang diajarkan mencakup tekhnis pembacaan dari beberapa lembar Al-Quran) ${ }^{7}$.

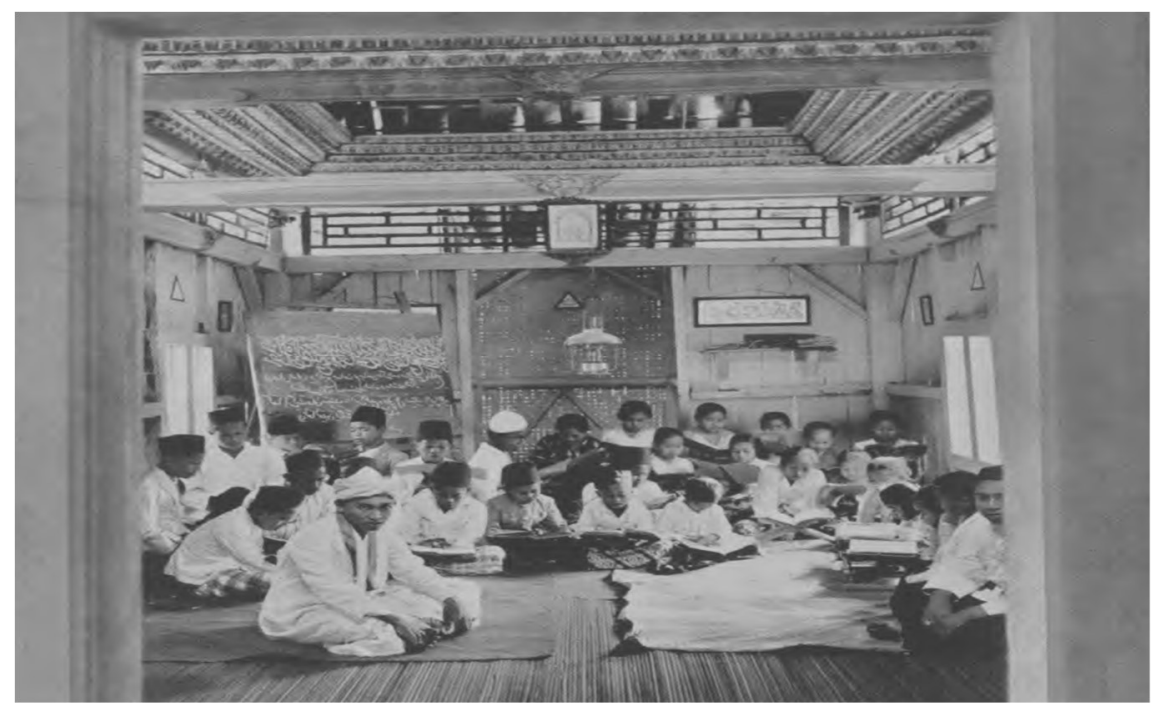

Potret anak-anak kecil yang sedang mengaji di sebuah langgar di Priangan ${ }^{8}$

Pada tingkatan yang lebih spesifik, pelaksanaan ajaran agama dalam kehidupan sehari-hari juga tidak terlepas dari tradisi yang mengiringinya. Sholat misalnya, setiap selesai sholat fardu berjama'ah, orang Sunda biasanya melaksanakan wiridan. Wiridan adalah serangkaian pembacaan kalimatkalimat suci. Bacaan tersebut adalah istighfar, membaca kalimah tasbih, tahmid dan takbir masing-masing sebanyak 33 kali, membaca sholawat, setelah itu ditutup dengan pembacaan doa. Bagi kalangan tarekat, jumlah bacaan tersebut akan ditambah dengan kalimat dzikir lailahaillallah sebanyak ratusan kali. Prosesi wiridan ini dipimpin oleh kyai atau seseorang yang telah bertindak selaku imam sholat dan diikuti oleh makmumnya.

Selain sholat lima waktu, masyarakat Islam Sunda taat dalam melaksanakan puasa. Di samping puasa pada bulan Ramadhan selama 40 hari sebagai kewajiban melaksanakan rukun Islam keempat, sebagian masyarakat Islam Sunda adakalanya melaksanakan puasa sunnah. Puasa sunnah itu antara

\footnotetext{
${ }^{7}$ C Spat, De Islam En Zijn Beteekenis Voor Nederlandsch-Indie (Breda: De Koninklijke Militaire Academie., 1925), 8-9.

8 Wijnand Kerkhoff, Het Paradisj Van Java (Leiden: Uit de verzamelingen van het Rijksmuseum voor Volkenkunde, n.d.), 6.
} 
lain, puasa nyenen kemis, puasa Daud, puasa nyawalan dan puasa $a r a f a h^{9}$. Tradisi lain yang berkembang dari ibadah puasa ini adalah puasa yang dilakukan atas dasar adanya keinginan yang hendak dicapai. Di kalangan para santri dikenal tradisi puasa mutih, yaitu hanya makan nasi dan minum air putih secukupnya dan puasa ngrowot yaitu hanya makan daun-daunan. Ada juga puasa patigeni yaitu puasa yang dalam beberapa hari tidak makan minum sama sekali, bahkan sekedar buka dan sahur pun tidak. Puasa-puasa tersebut biasanya merupakan bagian daripada proses pelaksanaan tirakat ${ }^{10}$. Sebagian umat Islam terutama kalangan ulama dan para santri percaya bahwa dengan berpuasa dan tirakat semacam itu sama artinya dengan melestarikan amalanamalan para wali yang menyebarkan Islam di pulau Jawa. Bahkan pada masa kolonial Belanda, para kyai dan santri-santrinya sering melakukan tradisi ini untuk tujuan memperoleh kesaktian. Hal itu demi melindungi diri dari kejahatan-kejahatan yang mungkin ditimbulkan oleh serdadu-serdadu Belanda.

Pada masyarakat Sunda, zakat juga menjadi bagian dari syariat yang diamalkan. Tradisi menunaikan zakat di masyarakat Sunda biasanya dengan menggunakan beras, yang kemudian dikumpulkan di panitia yang dipimpin seorang seorang tokoh agama setempat. Setelah terkumpul cukup banyak, beras zakat lalu dibagi-bagikan. Pada sekitar abad ke-19 kebiasaan menyalurkan zakat ini salah satunya dicatat dalam buku De Islam en zijn Beteekenis voor Nederlandsch-Indie, sebagai berikut:

...dit is het geval in de Pasoendan, waar de dorpspriesters als inners optreden. De moskeebeambten trekken dientengevolge in West Java hier en daar nog al aanzienlijke inkomsten uit de djakat (hal ini terjadi di Pasoendan, di mana para pemuka agama desa bertindak sebagai

\footnotetext{
${ }^{9}$ Puasa nyenen kemis adalah puasa yang dilakukan setiap hari senin dan kamis, mencontoh dari apa yang dilakukan oleh Rasulullah. Puasa Daud adalah puasa selang sehari selama waktu yang tidak ditentukan. Konon puasa ini adalah puasa yang dilakukan oleh Nabi Daud sepanjang hidupnya. Puasa nyawalan adalah puasa tujuh hari pada bulan Syawal, selepas Iedul Fitri. Puasa Arafah adalah puasa yang dilaksanakan menjelang Iedul Adha.

${ }^{10}$ Tirakat adalah meninggalkan suatu larangan yang telah ditentukan dalam jangka waktu tertentu, sekaligus menjalankan amalan-amalan tertentu dalam waktu, tempat dan cara tertentu pula. Contohnya seseorang ingin menguasai ilmu kanuragan, dia melakukan puasa patigeni selama tiga hari, membaca ayat kursi sebanyak seribu kali setiap ba'da shalat fardu, pada malam terakhir hanya berbuka dengan seteguk air dan tidak tidur sepanjang malam (Fadeli dan Subhan, 2007: 158-159).
} 
pengelola. Alhasil, para pengurus masjid di Jawa Barat mendapat pemasukan yang cukup besar dari hasil zakat) ${ }^{11}$

Religiusitas masyarakat Islam Sunda juga nampak jelas dalam berbagai tradisi upacara selamatan tahapan-tahapan hidup seseorang. Pada saat janin masih di dalam kandungan kedua orang tuanya akan melakukan ritual peringatan empat bulanan. Masyarakat Islam Sunda percaya bahwa pada usia empat bulan, Allah SWT akan meniupkan roh kepada jabang bayi. Oleh karena itu perlu dilaksanakan salametan, dengan mengundang tetangga dan kerabat untuk melakukan pengajian. Dalam prosesi pengajian ini, dibacakan doa-doa Nurbuat agar bayi dan ibunya sehat dan diberi keselamatan ${ }^{12}$. Ritual berlanjut ketika kandungan berumur tujuh bulan, yang biasa disebut tingkeban atau nujuh bulan. Tingkeban berasal dari kata "tingkeb" yang berarti tutup, maksudnya bahwa kesempatan untuk melakukan hubungan suami istri untuk sementara waktu ditutup. Adapun bentuk upacaranya adalah berupa pengajian Al Qur'an surat Yusuf, surat Maryam, surat Luqman dan surat Muhammad, dengan maksud mengambil berkah agar kelak si anak bisa meneladani tokohtokoh tersebut ${ }^{13}$.

Kemudian setelah bayi lahir, umur tujuh sampai dua puluh satu hari diaksanakan selamatan ekah atau aqiqah. Aqiqah berasal dari kata "aqiqatun"14. Aqiqah merupakan tradisi penyembelihan hewan sebagai tebusan atas tergadainya kesejatian hubungan batin antara orang tua dan anak. Dengan tebusan tersebut, dipercaya kelak anak itu menjadi anak sholeh yang dapat menolong kedua orang tuanya, baik di dunia maupun di akhirat. Ketentuannya, hewan yang disembelih adalah dua ekor kambing untuk anak laki-laki dan satu ekor kambing untuk anak perempuan. Selanjutnya kambing yang disembelih akan dimasak, lalu dibagikan kepada saudara dan tetangga. ${ }^{15}$

Pada saat bayi berusia empat puluh hari, dilaksanakanlah apa yang disebut marhabaan. Marhabaan adalah pembacaan syair-syair pujian kepada Nabi Muhammad yang terkandung dalam kitab Barzanji. Barzanji merupakan sebuah karya seni sastra berbentuk prosa dan puisi yang memuat kehidupan

\footnotetext{
${ }^{11}$ Spat, De Islam En Zijn Beteekenis Voor Nederlandsch-Indie, 27.

${ }^{12}$ Nina Herlina Lubis, Sejarah Kebudayaan Sunda (Bandung: Yayasan Masyarakat Sejarawan Indonesia Cabang Jawa Barat, 2015), 274-75.

${ }^{13}$ Soelaeman Fadeli and Mohammad Subhan, Antologi NU, Sejarah, Istilah, Uswah Dan Amaliah Jilid I. (Surabaya: Khalista, 2007), 158.

${ }^{14}$ Secara bahasa aqiqatun artinya rambut kepala bayi yang sudah tumbuh sejak lahir.

${ }^{15}$ Lubis, Sejarah Kebudayaan Sunda, 280.
} 
Nabi Muhammad SAW mulai dari masa sebelum kelahiran, silsilah keturunan, kehidupan masa kanak-kanak, masa remaja dan pemuda, hingga diangkat menjadi rasul. Juga menggambarkan sifat-sifat mulia rasul, kepribadian yang agung serta perjuangan menyebarkan Islam. Kitab Barzanji ditulis oleh Syeikh Ja'far Al-Barzanji bin Hasan bin Abdul Karim (1690-1764 M). Nama Barzanji dinisbatkan kepada nama desa Barzinja di kota Syahrazur Kurdistan Selatan. Kitab Barzanji yang berjudul asli Al-'Iqd Al-Jawahir ini sangat popular di dunia Islam, bahkan di Indonesia, kepopulerannya tetap terasa sampai sekarang. ${ }^{16}$

Adapun ritual seperti itu dimaksudkan untuk membersihkan atau mensucikan bayi dari segala macam najis, dengan cara menggunting rambut bayi secara simbolis. Pada pelaksanaannya bayi dibaringkan di tengah-tengah undangan disertai perlengkapan bokor yang diisi air kembang tujuh rupa dan gunting. Kemudian secara bergiliran hadirin memotong rambut dan mendoakan bayi, sambil bersama-sama melantunkan marhaba. Adapun potongan rambut tersebut akan ditimbang dan orang tuanya harus menyediakan emas seberat takaran rambut yang didapat. Kalaupun bukan berupa emas, maka kedua orang tua si bayi harus menyediakan uang seharga mas tersebut, lalu dibagikan kepada fakir miskin. ${ }^{17}$

Ketika tiba masa kanak-kanak, salah satu kewajiban bagi setiap muslim adalah dikhitan, dengan tujuan membersihkan alat vital dari najis. Pada masyarakat Islam Sunda, khitanan ini sering disebut selamatan sepitan atau sunatan. Untuk anak perempuan, sepitan dilakukan pada waktu ia masih bayi, biasanya ditangani oleh dukun beranak alias paraji. Sementara itu, anak laki-laki akan menjalani prosesi sepitan ketika ia menginjak usia empat sampai enam tahun, biasanya ditangani oleh seorang ahli khitan alias bengkong. Bagi sebagian orang Islam, percaya bahwa khitanan adalah kewajiban syariat yang pertama kali diturunkan kepada nabi Ibrahim, lalu kemudian disempurnakan oleh syariat nabi Muhammad melalui ajaran Islam.

Beranjak ke masa dewasa, tiba saatnya seseorang melewati prosesi pernikahan. Bagi orang yang akan menikah, memenuhi ketentuan syariat dan adat adalah suatu keharusan. Secara hukum fiqih, dalam Islam terdapat syarat sah nikah yang harus dipenuhi, yaitu dengan adanya wali, saksi, ijab kabul,

\footnotetext{
${ }^{16}$ Martin van Bruinessen, Kitab Kuning, Pesantren Dan Tarekat (Bandung: Mizan, 1995), 96-97.

${ }^{17}$ Lubis, Sejarah Kebudayaan Sunda, 281-82.
} 
dan mas kawin. Akad nikah sering dipimpin oleh seseorang yang ahli agama atau yang mempunyai kewenangan dalam menangani hukum munakahat, yang biasa disebut penghulu atau naib. Mas kawin yang diserahkan pihak mempelai lelaki kepada mempelai wanita juga akan sangat nampak Islami dengan kebiasaan memberikan emas dan seperangkat alat sholat dan AlQur'an. Selanjutnya, perkawinan yang dilaksanakan secara syariat Islam tersebut akan diiringi oleh rangkaian upacara adat. Meskipun bukan merupakan rukun dan syarat sah pernikahan, namun upacara adat semacam ngeuyeuk seureuh, sungkeman, saweran, nincak enog, buka pintu, dan huap lingkung ${ }^{18}$ lazim dilakukan sebelum atau sesudah akad nikah.

Ritual dalam tahapan kehidupan masyarakat Islam Sunda selanjutnya adalah berkaitan dengan kematian. Ketika seseorang meninggal dunia, keluarganya akan melaksanakan tradisi tahlilan. Tahlilan adalah tradisi doa bersama di rumah duka untuk membaca kalimah-kalimah thayibah atau membaca Al-Qur'an dengan maksud mendoakan orang yang sudah meninggal. Tahlilan dilaksanakan selama tujuh hari, di mana waktu yang

\footnotetext{
${ }^{18}$ Ngeuyeuk seureuh mengandung arti mengatur sirih. Perlengkapan yang digunakan berupa sirih beranting, setandan buah pinang dan tembakau. Ritual ini dimaksudkan menasehati kedua calon mempelai tentang pandangan dan cara menjalankan kehidupan rumah tangga berdasarkan etika dan agama. Sungkeman adalah tradisi bersimpuh di hadapan kedua orang tua mempelai untuk memohon restu. Saweran adalah ritual pembacaan syair-syair yang ditembangkan yang berisi pituah dan nasehat kepada kedua mempelai. Perlengkapan ritual ini adalah sebuah bokor yang berisi beras, uang logam, bunga dan permen. Upacara dipimpin oleh juru sawer. Di tengah-tengah menembangkan syair, juru sawer menaburkan isi bokor kepada pengantin atau kepada hadirin yang menyaksikan. Upacara nincak enog adalah tradisi menginjak telur, sebagai perlambang pengabdian seorang istri kepada suami. Perlengkapan yang disediakan antara lain lilin, tujuh buah harupat (lidi dari pohon aren), sebutir telur ayam metah, sebuah kendi berisi air dan batu pipisan. Pada pelaksanaannya, lilin dinyalakan, kemudian mempelai wanita menyalakan ujung harupat, lalu dibuang. Sementara mempelai pria menginjak telur dan menaruh kakinya di atas batu pipisan untuk dibasuh air kendi oleh mempelai wanita. Setelah selesai membasuh, kendi trersebut dibanting ke tanah sampai hancur. Upacara buka pintu adalah tradisi yang dilakukan dengan cara membiarkan mempelai wanita memasuki rumah, sementara mempelai pria ditahan terlebih dahulu di luar rumah. Mempelai wanita baru akan membukakan pintu apabila mempelai pria sudah membacakan syahadat. Setelah syahadat dibacakan dan pintu dibuka, maka selanjutnya mempelai pria memasuki rumah. Upacara ini mengandung makna bahwa mempelai pria adalah benar-benar beragama Islam. Tradisi huap lingkung adalah upacara yang dilakukan ketika kedua mempelai sedang berada di pelaminan. Di depan mereka disiapkan bakakak ayam (panggam ayam yang bagian dadanya dibelah dua). Mula-mula bakakak ayam ini dipegang oleh kedua mempelai, lalu saling tarik menarik hingga menjadi dua. Dalam prosesi ini diyakini bahwa siapa yang paling besar mendapatkan bagian potongan ayam, maka dialah yang akan mendapat rezeki paling banyak. Oleh sebab itu ritual ini diakhiri sengan cara saling menyuapi dengan maksud agar keduanya harus rela saling memberi dengan tulus dan ikhlas (Lubis, 2015: 285-288).
} 
dipergunakan adalah ba'da ashar atau ba'da maghrib pada setiap harinya. Kemudian sanak famili akan memperingati kematian si mayit pada empat puluh dan seratus hari pasca kematian dalam tradisi yang disebut matang puluh dan natus. Ada juga tradisi haolan. Haolan adalah peringatan kematian seseorang pada setiap tahun yang waktu pelaksanaannya bertepatan dengan tanggal dan bulan wafat orang yang diperingati. Acara haol seringkali diisi dengan pembacaan tahlil dan doa bersama, serta adanya pembagian sedekah dari yang punya hajat. Apabila yang diperingati tersebut adalah seorang tokoh agama maka biasanya haolan sering diselenggarakan dalam skala yang lebih besar, seperti diadakan seminar, tabligh akbar atau musabaqoh (perlombaan) keagamaan $^{19}$.

Tradisi haol berkaitan erat dengan ritual-ritual berorientasi makam, di mana yang terpenting adalah ziarah qubur. pada masyarakat Islam Sunda dikenal tradisi ziarah qubur. Ziarah qubur adalah tradisi mendatangi makammakam orang tua, karuhun, para ulama, para wali dan sebagainya untuk mendoakan dan ngalap barokah. Setidaknya setahun dua kali masyarakat Islam Sunda akan melakukan ziarah, yaitu pada sesudah pelaksanaan Iedul Fitri dan Iedul Adha. Sebagian masyarakat Islam Sunda percaya bahwa pahala dari bacaan-bacaan doa tersebut akan sampai kepada ahli qubur dan juga diberikan kepada orang yang memanjatkannya. Mereka juga percaya bahwa kebiasaan ziarah qubur ini akan semakin mengingatkan manusia pada kematian $^{20}$.

Hasil yang didapat dari ziarah qubur adalah berupa keberkahan apabila menziarahi makam para ulama, para wali dan orang-orang soleh. Di Jawa Barat, makam para ulama besar, makam para wali penyebar Islam dan makam para menak kerap menjadi tujuan para peziarah. Terutama pada waktu-waktu tertentu, seperti bulan mulud, bulan Romadhon atau pasca lebaran Iedul Fitri, jumlah para peziarah biasanya akan mengalami lonjakan. Tempat ziarah paling terkenal di Jawa Barat adalah makam Sunan Gunung Jati, tokoh utama penyebar Islam di Jawa Barat yang makamnya terletak di bukit Sembung Cirebon. Dalam wacana kaum tradisionalis mengenai ziarah dipercaya bahwa para wali dan ulama yang sudah meninggal mampu meneruskan barokah dari Tuhan $^{21}$.

\footnotetext{
${ }^{19}$ Fadeli and Subhan, Antologi NU, Sejarah, Istilah, Uswah Dan Amaliah Jilid I., 119-20.

${ }^{20}$ Jajat Burhanudin, Ulama Dan Kekuasaan, Pergumulan Elite Muslim Dalam Sejarah Indonesia (Jakarta: Mizan, 2012), 354.

${ }^{21}$ Burhanudin, 354.
} 
Selain Sunan Gunung Jati, para penyebar Islam di tanah Sunda lain yang makamnya kerap dijadikan sebagai tempat ziarah adalah makam Kian Santang di Garut dan makam Syaikh Abdul Muhyi Pamijahan Tasikmalaya. Oleh Dennys Lombard makam keramat dari kedua tokoh tersebut dideskripsikan sebagai berikut:

Di sebelah Timur Pasundan, tepatnya di daerah-daerah aliran sungai kecil di pedalaman yang cocok untuk pesawahan, yaitu Garut (dahulu Limbangan), Sumedang dan Tasikmalaya (dahulu Sukapura), juga tersimpan akan kenangan pendiri-pendiri saleh yang datang dari Cirebon untuk membawa masuk agama Islam. Di Godog, kira-kira $15 \mathrm{~km}$ dari Garut, terletak makam Kian Santang, salah seorang putera Prabu Siliwangi, raja kafir terakhir di negeri itu, yang konon pergi ke Mekkah untuk mempelajari agama baru itu dan kemudian menyebarkan ke daerah Limbangan... kira-kira empat puluh kilometer di selatan Tasikmalaya, di lembah Pamijahan yang memukau, masih terdapat makam Syaikh Abdul Muhyi yang membuka hutan di tempat terpencil di daerah Priangan ini, tidak terlalu jauh dari pantai selatan. Dari segala penjuru Pasundan orang datang berziarah; dan sesudah melewati jalan yang buruk, pemandangan pesawahan berundak di sekeliling tampil sebagai suatu tempat teduh penuh pesona ${ }^{22}$.

22 Dennys Lombard, Nusa Jawa Silang Budaya Jilid 2: Jaringan Asia (Jakarta: Gramedia Pustaka Utama, 2008), 128. 


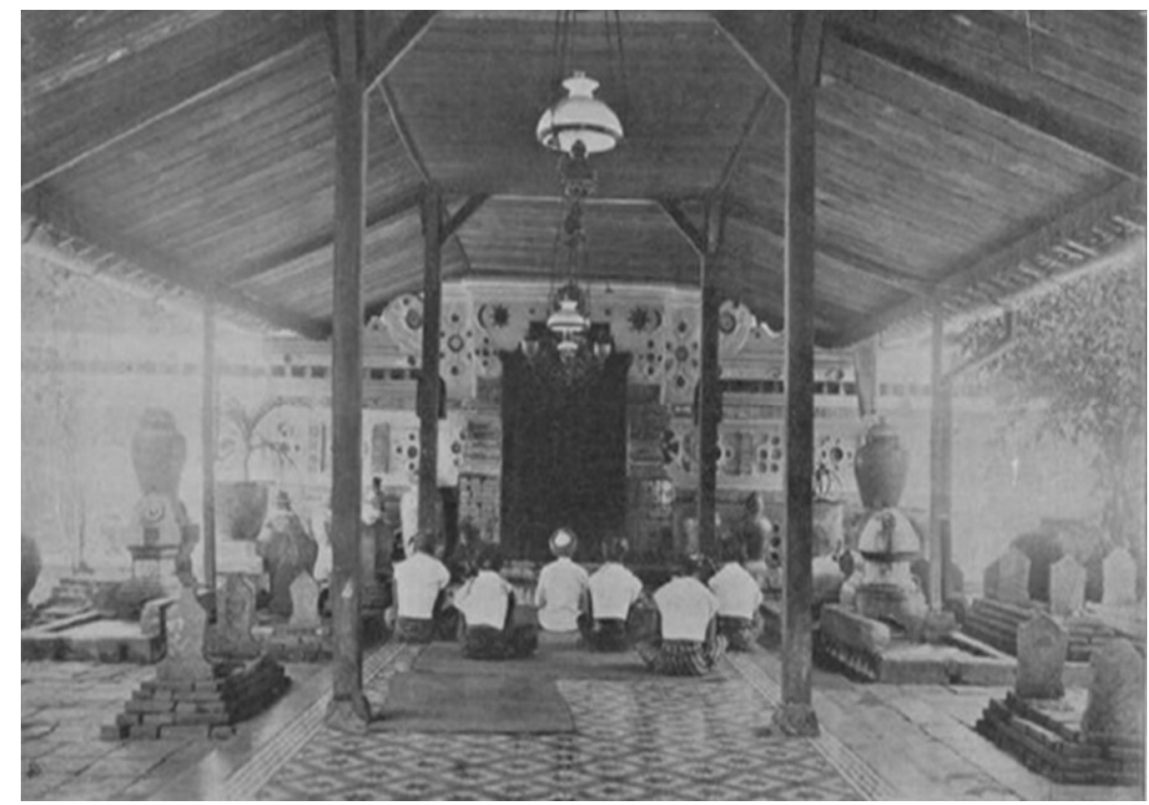

Para peziarah sedang memanjatkan doa di serambi makam Sunan Gunung Jati ${ }^{23}$

Di samping berbagai tradisi yang berkaitan dengan tahapan hidup seperti telah dipaparkan di atas, pada sebagian masyarakat Islam Sunda juga terdapat tradisi memuliakan tanggal, hari dan bulan tertentu. Hal ini dilakukan karena suatu kepercayaan bahwa tanggal, hari atau bulan tertentu ada yang lebih mulia atau memiliki keistimewaan dibandingkan waktu lainnya. Hingga saat ini, kebanyakan orang Islam percaya bahwa malam Jum'at adalah waktu yang "sakral" untuk melakukan keutamaan-keutamaan dalam ibadah. Pada malam Jum'at tradisi yang biasa dilakukan oleh sebagian umat Islam Sunda adalah tawasulan. Tawasulan adalah tradisi menjadikan sesuatu sebagai perantara untuk mendekatkan diri kepada Allah. Biasanya dilakukan dengan mendoakan orang-orang shaleh, para karuhun, para wali, para sahabat dan para nabi, dengan harapan keberkahan yang telah Allah berikan kepada orangorang sholeh tersebut, diberikan juga kepada orang yang mendoakannya. Dalam tawasulan ini sering diikuti pembacaan surat yaasin yang oleh orang Sunda disebut dengan istilah yaasinan.

Selain hari, ada juga bulan yang diistimewakan, salah satunya adalah bulan Maulud (Mulud dalam lafal orang Sunda). Banyak amaliah dan ritual

\footnotetext{
${ }^{23}$ Masdjid Dan Makam Doenia Islam, 60.
} 
keagamaan yang dianjurkan berikut pantangannya, dilaksanakan hanya pada bulan Maulud dan tidak dilakukan pada bulan-bulan lain. Misalnya, pada bulan ini beberapa barang pusaka atau keramat, sperti keris, golok, kujang, pedang, cincin batu akik, dimandikan dengan air kembang tujuh rupa. Di beberapa pesantren, bulan Maulud juga sering dijadikan sebagai waktu untuk mematangkan ilmu penca, ilmu kebal atau ilmu kanuragan lainnya. Bacaanbacaan yang diamalkan untuk mencapai ilmu itu disebut $h_{i z i b}{ }^{24}$.

Dalam tahun 1880-an sampai abad ke-20, di beberapa daerah di Priangan, menyebut tanggal 12 Maulud sebagai malam walilat. Sebutan itu diambil dari kalimat takbir yang biasa dikumandangkan sewaktu iedul fitri dan iedul adha; "Allahu Akbar Walillat (h) hilhamd." Pada malam itu banyak orang memberi sidkah dengan maksud menghormati kelahiran Nabi Muhammad. Bagi sebagian yang mampu, walilat dilakukan dengan menggelar hajatan. Dalam kesempatan itu, barang pusaka yang sering disebut pakarang kabuyutan diikutsertakan dalam upacara ${ }^{25}$.

Selanjutnya ada beberapa tradisi keagamaan yang skala pelaksanaannya lebih besar, seperti peringatan nuzulul Qur'an, istighotsahan dan manaqiban. Peringatan Nuzulul Qur'an adalah peringatan atas turunnya Al-Qur'an yang biasa dilakukan pada setiap tanggal 17 Ramadhan. Pada malam 17 Ramadhan selepas shalat tarawih, umat Islam berkumpul di masjid untuk membaca Al-Qur'an bersama-sama. Kemudian mereka mendengarkan ceramah dari seorang kyai yang memaparkan segala sesuatu yang berkaitan dengan Al-Qur'an. Jika peringatan nuzulul qur'an dilaksanakan dengan membaca Al-qur'an bersama-sama, Istighotsah adalah mohon pertolongan Allah secara masal. Ini dilakukan ketika menghadapi permasalahan yang besar dan jalan yang ditempuh semakin sulit. Dalam proses istighotsah, para jama'ah yang hadir akan membaca secara berulang-ulang berbagai rangkaian kalimat-kalimat suci yang bacaannya sudah dibakukan oleh para ulama ${ }^{26}$. Sementara itu, manaqiban adalah tradisi mengambil pelajaran dari kisah-kisah para wali, terutama Syeikh Abdul Qadir Jaelani yang dianggap sebagai wali

\footnotetext{
${ }^{24}$ Hizib adalah rangkaian doa-doa khusus yang disusun oleh para ulama atau kyai yang memiliki keistimewaan tersendiri. Biasanya berisi sholawat, istighfar, potongan ayat-ayat alqur'an, asmaul husna dan sebagainya, yang dilakukan dengan cara tertentu, jumlah tertentu dan dalam waktu tertentu pula. Jika sudah tercapai, maka si pengamal hizib akan memperoleh kesitimewaan seperti dapat mengobati orang gila dan kesurupan, dapat kebal senjata dan tahan pukulan serta dapat menangkal ilmu santet.

${ }^{25}$ Muhammad Iskandar, Para Pengemban Amanah (Jogjakarta: Mata Bangsa, 2001), 53.

${ }^{26}$ Fadeli and Subhan, Antologi NU, Sejarah, Istilah, Uswah Dan Amaliah Jilid I., 122.
} 
tertinggi oleh kalangan Islam tradisional. Penekanan dari tradisi ini bertujuan memperoleh pahala yang banyak, serta keuntungan spiritual dan material ${ }^{27}$.

Tradisi lain yang masuk kategori syiar Islam dan peringatan hari besar Islam adalah peringatan Isra' Mi 'raj dan peringatan Maulid Nabi Muhammad. Peringatan Maulid Nabi Muhammad dan Isra' Mi'raj merupakan tradisi yang paling disenangi di wilayah Priangan ${ }^{28}$. Peringatan Isra' Mi'raj adalah suatu acara yang diselenggarakan untuk mengenang peristiwa perjalanan Nabi Muhammad dari masjid Al-Harom di Makkah ke masjid Al-Aqso di Palestina dan kemudian naik ke langit untuk menerima perintah shalat dari Allah. Sementara itu, peringatan Maulid Nabi adalah tradisi besar umat Islam untuk memperingati hari kelahiran Nabi Muhammad, pada setiap tanggal 12 Rabi'ul Awal. Baik peringatan Isra' Mi'raj maupun peringatan Maulid Nabi, biasanya kedua acara ini diselenggarakan dengan sangat meriah, bentuk perayaannya, setiap daerah memiliki ciri khas masing-masing.

Pada masyarakat Islam Sunda, prosesi peringatan Isra' Mi'raj dengan Maulid Nabi biasanya berupa tabligh akbar yang ceramahnya diisi oleh mubalig-mubalig kondang. Para kyai, ajengan atau ulama khos dari daerah lain atau dari pesantren tertentu, diundang untuk memberikan penerangan di depan khalayak umum. Jika diperhatikan, di Indonesia kedua acara ini sudah menjadi acara resmi kenegaraan, seluruh instansi pemerintahan dari pusat sampai daerah selalu menyelenggarakan pada setiap tahunnya, bahkan dari sebelum Indonesia merdeka. Pijper memberikan ilustrasi tentang bagaimana peringatan Isra' Mi'raj di daerah Priangan yang melibatkan pihak pemerintah sebagai berikut:

Dari alun-alun datanglah barisan kecil yang didahului oleh seorang pengawal yang membawa lampu. Di depannya berjalan istri wedana, istri naib dan istri pengawal rendah lainnya yang diikuti oleh para pejabat. Para wanita memasuki masjid melalui pintu samping. Setelah para pejabat mengambil tempat di atas permadani di depan pintu masjid, upacara pun dimulai. Yang memimpin upacara adalah seorang kyai dari pesantren di daerah itu. Ia memakai jubbah berwarna merah jambu dan duduk di tengah-tengah serambi depan, menghadap ke masjid. Beberapa kitab tentang cerita Mikraj yang nanti akan dibaca,

\footnotetext{
${ }^{27}$ Bruinessen, Kitab Kuning, Pesantren Dan Tarekat, 169.

${ }^{28}$ Ading Kusdiana, Sejarah Pesantren; Jejak, Penyebaran, Dan Jaringannya Di Wilayah Priangan 1800-1945 (Bandung: Humaniora, 2014), 44-51.
} 
terbuka dan terletak di atas tumpukan bantal. Kyai memberi tanda, kemudian 5 orang santri yang masih muda menyajikan lagu pujian untuk Nabi Muhammad SAW. Kemudian kyai memulai ceramahnya dengan membaca basmalah, shalawat pada Nabi Muhammad SAW dan ayat pertama surat Al-Isra (XVII) ${ }^{29}$.

Masyarakat Islam Sunda juga melaksanakan ibadah haji. Kegiatan pelaksanaan ibadah haji sebagai menifestasi dari rukun Islam ke-5 ini sudah banyak dilakukan sejak abad ke-19. Masyarakat Islam Sunda percaya bahwa menunaikan ibadah haji adalah wajib setidaknya sekali seumur hidup bagi yang mampu. Mereka juga meyakini bagi orang yang mampu tapi selama hidupnya tidak pernah melaksanakan haji, maka hal tersebut akan menjadi hutang yang akan ditagih kelak di akhirat. Tradisi yang mengiringi prosesi ibadah haji ini adalah walimatussafar, yaitu sebelum berangkat, seorang calon haji mengundang tetangganya untuk mengadakan doa bersama lalu kemudian diberikan sedekah. Pada umumnya, para haji sepulang dari tanah suci kerap memakai pakaian putih-putih. Bahkan ada sebagian yang mengidentikkan dirinya menjadi ala arab dengan memakai gamis dan sorban putih. Mereka juga berusaha untuk menjadi lebih taat dalam menjalankan perintah agama.

Fanatisme agama yang ditunjukkan para haji sepulang dari Tanah Suci kerap menjadi perhatian Pemerintah Kolonial Belanda. Jika di Aceh ada Snouck Hougronje, maka di Sunda ada tokoh bernama K.F. Hole yang pada tahun 1871 ditugaskan oleh Pemerintah Kolonial Belanda untuk menduduki jabatan penasihat kehormatan untuk urusan-urusan masyarakat pribumi. Holle yang sejatinya telah lama berinteraksi mengenal masyarakat Islam Sunda, dia melancarkan sebuah proyek yang bertujuan mengurangi pengaruh Islam bagi muslim di Hindia Belanda. Pada 1873 ia berangkat ke Singapura untuk mengukur dampak pan-Islamisme terhadap meningkatnya semangat jihad anti-Belanda, serta menyelidiki pengaruh haji terhadap gerakan orang-orang Islam. Ia sampai pada kesimpulan bahwa para haji bertanggung jawab atas fanatisme Islam di Hindia Belanda ${ }^{30}$. Sementara itu, jumlah umat Islam di

\footnotetext{
${ }^{29}$ Kusdiana, 52.

${ }^{30}$ Burhanudin, Ulama Dan Kekuasaan, Pergumulan Elite Muslim Dalam Sejarah Indonesia, 162.
} 
Jawa Barat yang berangkat haji yang dapat dilihat dari catatan laporan Holle adalah di antaranya sebagai berikut: ${ }^{31}$

\begin{tabular}{|c|c|c|c|c|c|c|c|c|c|c|c|}
\hline & \multicolumn{10}{|c|}{ Jumlah Haji Dalam Tahun } \\
\cline { 2 - 13 } Daerah & $\begin{array}{c}187 \\
6\end{array}$ & $\begin{array}{c}187 \\
7\end{array}$ & $\begin{array}{c}187 \\
8\end{array}$ & $\begin{array}{c}187 \\
9\end{array}$ & $\begin{array}{c}188 \\
0\end{array}$ & $\begin{array}{c}188 \\
1\end{array}$ & $\begin{array}{c}188 \\
2\end{array}$ & $\begin{array}{c}188 \\
3\end{array}$ & $\begin{array}{c}188 \\
4\end{array}$ & $\begin{array}{c}188 \\
5\end{array}$ & $\begin{array}{c}188 \\
6\end{array}$ \\
\hline Banten & 415 & 378 & 607 & 295 & 666 & 339 & 273 & 198 & 280 & 98 & 94 \\
\hline Batavia & 304 & 323 & 283 & 107 & 196 & 217 & 142 & 167 & 223 & 260 & 165 \\
\hline $\begin{array}{c}\text { Prianga } \\
\text { n }\end{array}$ & 598 & 813 & 660 & 843 & 250 & 498 & 707 & 935 & 576 & 254 & 92 \\
\hline $\begin{array}{c}\text { Karawa } \\
\text { ng }\end{array}$ & 8 & 12 & 12 & 3 & 42 & 11 & 16 & 12 & 11 & 5 & 3 \\
\hline $\begin{array}{c}\text { Cirebo } \\
\mathrm{n}\end{array}$ & 231 & 521 & 144 & 148 & 485 & 111 & 329 & 153 & 68 & 65 & 75 \\
\hline
\end{tabular}

Terakhir, pengaruh Islam yang telah meresap ke dalam kebudayaan masyarakat Sunda juga nampak pada kesenian rakyat. Di Banten kesenian yang paling popular hasil dari perpaduan unsur Islam dengan tradisi setempat adalah debus. Debus adalah penanaman kekebalan tubuh dari api, bendabenda tajam atau dari apapun yang dapat merusak tubuh. Ilmu ini diperoleh dengan mengamalkan bacaan-bacaan Islami yang berbahasa Arab bercampur bacaan-bacaan berbahasa Jawa atau Sunda kuno semacam jampi, jangjawokan dan pelet $^{32}$. Kesenian lain yang tersebar di wilayah Jawa Barat adalah seperti tagoni, doblang, genjingan, rudat, terbang muludan dan terbang barzanji, yang cukup popular pada abad ke-19 dan awal abad ke-20 $0^{33}$.

\section{Simpulan}

Jika dilihat dari perilaku keberagamaan masyarakat Islam Sunda, terutama yang mendiami wilayah pedesaan dan perkampungan, nampaknya batasan antara unsur agama dengan unsur budaya sudah terasa bias. Ajaran Islam dengan adat istiadat setempat seperti telah terintegrasikan menjadi satu

\footnotetext{
${ }^{31}$ Karel Steenbrink, Beberapa Aspek Tentang Islam Di Indonesia Abad Ke-19 (Jakarta: Bulan Bintang, 1984), 251.

${ }^{32}$ Bruinessen, Kitab Kuning, Pesantren Dan Tarekat, 276-77.

${ }^{33}$ Iskandar, Para Pengemban Amanah, 55.
} 
dalam sistem kepercayaan, serta ditanggapi dengan emosi yang sama. Baik agama maupun tradisi setempat, masih dijalankan oleh masyarakat Sunda sebagai fungsi pengatur sikap dan sistem nilai.

Dalam konteks religiusitas masyarakat Islam Sunda, tradisi lama yang mengandung kearifan lokal (local-genius), justru semakin kuat setelah berasimilasi dengan ajaran Islam. Diterimanya Islam dengan baik di tatar Sunda karena di antara keduanya mempunyai persamaan paradigma. Islam memandang dan memahami dunia sebagai ungkapan azas-azas mutlak dan terekam dalam wahyu Allah. Sedangkan kebudayaan Sunda lama meletakkan nilai-nilai mutlak yang kemudian diwujudkan dalam adat beserta berbagai upacaranya. Dari akulturasi dan harmoni di antara keduanya itu, hadirlah sebuah bentuk kebudayaan yang khas dan unik; budaya Sunda yang Islami.

\section{Daftar Sumber}

Bruinessen, Martin van. Kitab Kuning, Pesantren Dan Tarekat. Bandung: Mizan, 1995.

Burhanudin, Jajat. Ulama Dan Kekuasaan, Pergumulan Elite Muslim Dalam Sejarah Indonesia. Jakarta: Mizan, 2012.

Fadeli, Soelaeman, and Mohammad Subhan. Antologi NU, Sejarah, Istilah, Uswah Dan Amaliah Jilid I. Surabaya: Khalista, 2007.

Garraghan, Gilbert J.S.J. A Guide To Historical Method. New York:

Fordham University Press, 1957.

Iskandar, Muhammad. Para Pengemban Amanah. Jogjakarta: Mata Bangsa, 2001.

Kerkhoff, Wijnand. Het Paradisj Van Java. Leiden: Uit de verzamelingen van het Rijksmuseum voor Volkenkunde, n.d.

Kusdiana, Ading. Sejarah Pesantren; Jejak, Penyebaran, Dan Jaringannya Di Wilayah Priangan 1800-1945. Bandung: Humaniora, 2014.

Lombard, Dennys. Nusa Jawa Silang Budaya Jilid 2: Jaringan Asia. Jakarta: Gramedia Pustaka Utama, 2008.

Lubis, Nina Herlina. Sejarah Kebudayaan Sunda. Bandung: Yayasan

Masyarakat Sejarawan Indonesia Cabang Jawa Barat, 2015.

—. Sejarah Perkembangan Islam Di Jawa Barat. Bandung: Yayasan

Masyarakat Sejarawan Indonesia Jawa Barat, 2011.

Masdjid Dan Makam Doenia Islam. Weltervreden: Balai Pustaka, 1926. Romli, Usep. "Menyambut Muktamar Nu Ke 33." Opini Pikiran Rakyat, 
Tradisi Keislaman Masyarakat Sunda pada Abad Ke-19|Agung Purnama

July 30, 2015.

Spat, C. De Islam En Zijn Beteekenis Voor Nederlandsch-Indie. Breda: De Koninklijke Militaire Academie., 1925.

Steenbrink, Karel. Beberapa Aspek Tentang Islam Di Indonesia Abad Ke-19. Jakarta: Bulan Bintang, 1984.

Wahid, Abdurrahman. Islamku, Islam Anda, Islam Kita, Agama Masyarakat Negara Demokrasi. Jakarta: Wahid Institut, 2006. 